\title{
EDITORIAL
}

\section{SLEEP AND DEMENTIA}

\author{
A. GABELLE 1,2, Y. DAUVILLIERS 1,2
}

1. Service de Neurologie, Hôpital Gui-de-Chauliac; 2. INSERM U888, Montpellier, France. For correspondance : Professor Yves Dauvilliers, Service de Neurologie, Unité des troubles du sommeil, CHU Gui de Chauliac, 80 Avenue Augustin Fliche, 34295 Montpellier, France. Tel +33 467 33 72 85, email : y-dauvilliers@ chu-montpellier.fr

Alzheimer's disease (AD) is a neurodegenerative disorder characterized by significant cognitive deficits, behavior changes, and loss of functional autonomy. The number of patients suffering from AD is growing rapidly as the world's population ages. The disease has become a major public health issue. Memory impairment is usually the earliest and core symptom of the disease. However, the presence of certain symptoms, especially early during the course of the disease can be misleading for clinicians. Nowadays, AD diagnosis is based on the combination of neurological, neuropsychological, morphological and/or functional brain imaging, and CSF biomarkers in some atypical cases. However, optimal therapeutic care for $\mathrm{AD}$ must focus on the development and characterization of new biomarkers for a positive diagnosis of the Alzheimer process, especially in the early stage of the disease. Recent advances on prodromal AD diagnostic criteria and determination of conversion factors reflect the importance of an early diagnosis.

Among the non-cognitive symptoms, sleep complaints are frequent problems in $\mathrm{AD}$ ranging from $25 \%$ to $35 \%$ of patients (for review, see Dauvilliers 2007) (1). The sleep patterns observed in $\mathrm{AD}$ patients are often similar to those observed in non-demented elderly but alterations are more severe. Nocturnal sleep disruption and daytime sleepiness are the main problems resulting from a phase advance and a decrease in the normal circadian rhythm, a reduced threshold in arousal from sleep, and environmental, psychological and iatrogenic factors. Sleep disturbances are frequently correlated with the severity of AD but may also be present at earlier stages of the disease. Hence, the prevalence of clinically-assessed sleep disturbances ranged from 14 to $59 \%$ in mild cognitive impairment (2). Last year, we reported in this journal most of sleep disorders observed in healthy and dependent older adults and discussed the potential sleep disturbances in frail older adults and its consequences on this weakened population (3). The relevance in assessing sleep disorders and the impact of sleep on neurodegenerative disorders including AD is increasing. In this issue of Journal of Nutrition, Health and Aging, three review articles focused on sleep and dementia interactions (4-6).

Bombois and their colleagues published a comprehensive review on the association between dementia and sleep disorders including insomnia (mainly secondary to medical, psychosocial comorbidities or multiple medications), daytime sleepiness, rapid eye movement (REM) sleep behaviour disorder, sundowning, restless legs syndrome, periodic leg movements and sleep-disordered breathing (4). Etiologies of sleep disturbances in patients with $\mathrm{AD}$ is thought to be multifactorial and include components specific to dementia and a number of nonspecific factors associated with the normal aging process. The acetylcholine level, molecule involved in the pathophysiology of AD, varies in function of sleep stages, higher during wake and REM sleep compared to slow wave sleep (SWS). The circadian rhythm disruption in AD may be related to suprachiasmatic nucleus lesions induced by the Alzheimer process per se. Sleep apnea induces sleep fragmentation and intermittent hypoxemia with important consequences at metabolic, cardiovascular and neuronal levels. The neuronal fragility induced by hypoxemia seems to play a role in patients' cognitive decline. Sundowning corresponds to a marked increase in problematic behavior, agitation and confusion in the late afternoon or evening with huge variability in its frequency ranging from $2 \%$ to $60(7,8)$.

Another review focusing on sleep disturbances in nursing home settings was published in this issue by Neikrug and Ancoli-Israel (5). Although prevalent in older adults, sleep complaints appear even more frequent and severe in subjects being matched for age and living in nursing homes. Factors that contribute to sleep complaints include circadian rhythms, sleep disorders per se, dementia, depression, medical and psychiatric conditions, polymedications and environment influences. Hence, nighttime sleep disruption, poorer sleep efficiency and daytime sleepiness were higher in nursing home residents with dementia compared to those without dementia. Disturbed sleep may have significant impact on the patient's cognitive and physical function and may be associated with distress and depression in both patients and caregivers. In addition, the presence of severe sleep disturbances is at high risk of institutionalization. Based on these considerations, management of sleep disturbances is important in dementia.

Most of the sleep impairment could be improved with pharmacologic and non-pharmacologic treatments such as sleep hygiene, bright light therapy or continuous positive airway pressure (CPAP). The paper from David and colleagues in this issue provides a review on the multiple non-pharmacological approaches of sleep/wake disturbances in AD (6). Sleep hygiene, sleep restriction and/or a more structured cognitive behavioural therapy were proposed in AD with successful results in decreasing nighttime awakenings and daytime sleep episodes $(9,10)$. Bright light therapy may be an effective treatment option for patients with disturbed sleep-wake 


\section{EDITORIAL}

patterns with improvements in sleep fragmentation, daytime sleepiness, depression and cognitive performances (11-13). Recent randomized controlled-trials using melatonin reported also some improvements in the sleep/wake patterns in $\mathrm{AD}$ (13, 14). Finally, preliminary studies suggest that treatment of obstructive sleep apnea by CPAP was well-tolerated, reduced daytime sleepiness; and may improve cognitive performances in mild to moderate $\mathrm{AD}$ patients $(15,17)$.

The neurobiology of sleepiness and sleep fragmentation is still a mystery, interactions between sleep and dementia being even more unexplained. However, the three cited reviews in this issue confirmed that our knowledge in the field of sleep disorders in older adults and in dementia has increased in recent years (4-6). The challenges of coming decades will be to optimize the understanding of the role of sleep in the cognitive process and its potential implication at earlier stages and in presence of particular behaviors in AD. Future studies are likely to evaluate whether 1) sleep disorders predispose patients to $\mathrm{AD}, 2$ ) $\mathrm{AD}$ can produce sleep disorders, and 3) the management of sleep disturbances in these patients can modify the prognosis of $\mathrm{AD}$ process per se. This increase in knowledge should be used to define treatment goals and to produce evidence-based guidelines for the management of sleep problems in patients with AD.

Conflict of interest: Pr. Dauvilliers has consulted for UCB Pharma, Sanofi-Aventis, Cephalon, Bioprojet, and Boehringer Ingelheim.

\section{References}

1. Dauvilliers Y. Insomnia in patients with neurodegenerative conditions. Sleep Med 2007; 8: 27-34.
2. Beaulieu-Bonneau, S, Hudon, C. Sleep disturbances in older adults with mild cognitive impairment. Int Psychogeriatr 2009;21: 654-666.

3. Cochen V, Arbus C, Soto ME, Villars H, Tiberge M, Montemayor T, Hein C, Veccherini MF, Onen SH, Ghorayeb I, Verny M, Fitten LJ, Savage J, Dauvilliers Y, Vellas B. Sleep disorders and their impacts on healthy, dependent, and frail older adults. J Nutr Health Aging. 2009;13:322-9.

4. Bombois S, Derambure P, Pasquier F, Monaca C. Sleep disorders in aging and dementia. J Nutr Health Aging. 2010; 14(3):212-217.

5. Neikrug A, Ancoli-Israel S. Sleep disturbances in nursing homes. J Nutr Health Aging. 2010; 14(3):207-211.

6. David R, Zeitzer J, Friedman L, Noda A, O'Hara R, Robert P, Yesavage J. Nonpharmacologic management of sleep disturbance in Alzheimer's disease. J Nutr Health Aging. 2010; 14(3):203-206

7. Martin J, Marler MR, Shochat T, et al. Circadian rhythms of agitation in institutionalized patients with Alzheimer's Disease. Chronobiol Intl 2000;17:405-418.

8. Vitiello MV, Bliwise DL, Prinz PN. Sleep in Alzheimer's disease and the sundown syndrome. Neurology 1992;42(7 suppl 6):83-93.

9. McCurry SM, Gibbons LE, Logsdon RG et al. Nighttime insomnia treatment and education for Alzheimer's disease. J Am Geriatr Soc 2005; 53: 793-802.

10. Shub D, Darvishi R, Kunik ME. Non-pharmacologic treatment of insomnia in persons with dementia. Geriatrics 2009; 64: 22-26.

11. Satlin A, Volicer L, Ross V, et al. Bright light treatment of behavioral and sleep disturbances in patients with Alzheimer's Disease. Am J Psychiatry 1992;149:10281032.

12. Burns A, Allen H, Tomenson B, et al. Bright light therapy for agitation in dementia: a randomized controlled trial. Int Psychoger 2009;21:711-721.

13. Riemersma-van der Lek R, Swaab DF, Twisk J, et al. Effect of bright light and melatonin on cognitive and noncognitive function in elderly residents of group care facilities: a randomized controlled trial. JAMA 2008;299:2642-2655.

14. Singer C, Tractenberg RE, Kaye J, Schafer K, Gamst A et al. A multicenter, placebo-controlled trial of melatonin for sleep disturbance in Alzheimer's disease. Sleep 2003; 26: 893-901

15. Martin JL, Mory AK, Alessi CA. Nighttime oxygen desaturation and symptoms of sleep-disordered breathing in long-stay nursing home residents. The journals of gerontology 2005;60:104-108.

16. Ancoli-Israel, S, Palmer, BW, Cooke, JR, Corey-Bloom, J, Fiorentino, L, Natarajan, L, Liu, L, Ayalon, L, He, F \& Loredo, JS. Cognitive effects of treating obstructive sleep apnea in Alzheimer's disease: a randomized controlled study. J Am Geriatr Soc 2008; 56: 2076-2081.

17. Chong, MS, Ayalon, L, Marler, M, Loredo, JS, Corey-Bloom, J, Palmer, BW, Liu, L \& Ancoli-Israel, S. Continuous positive airway pressure reduces subjective daytime sleepiness in patients with mild to moderate Alzheimer's disease with sleep disordered breathing. J Am Geriatr Soc 2006;54: 777-781. 